\title{
Articles
}

\section{Romantic Relationship Commitment and Its Linkages with Commitment to Parents and Friends during Adolescence}

Irene H. A. De Goede, The Netherlands Institute for Social Research, Susan Branje, Utrecht University, Jet van Duin, Utrecht University, Inge E. VanderValk, Utrecht University, and Wim Meeus, Utrecht University

\begin{abstract}
This five-wave longitudinal study examines linkages between adolescents' perceptions of romantic relationship commitment and the development of adolescents' perceptions of commitment to parents and friends. A total of 218 early-to-middle adolescents $(39.0$ percent boys) and 185 middle-to-late adolescents (30.8 percent boys) participated. Multivariate growth curves showed that higher base levels of commitment and a stronger positive development of commitment to parents and friends were associated with higher levels of later commitment to romantic partners. The effects were equally strong in early-to-middle adolescence and middle-to-late adolescence. Also, commitment to parents and commitment to friends were associated equally strong to romantic relationship commitment. No gender differences were found regarding these linkages. Overall, this study shows the importance of parents and friends for boys and girls regarding committed romantic relationships. The results support the idea of one stable and general working model used in different types of relationships.
\end{abstract}

Keywords: parent-adolescent relationships; friendships; romantic relationships; growth curves

\section{Introduction}

During adolescence, the formation of romantic relationships and the development of commitment and intimacy towards a romantic partner are among the most important developmental tasks (Bouchey \& Furman, 2003; Erikson, 1968). Because romantic involvements are supposed to form a source of support and positive emotions, they generally are important for adolescent development (Bouchey \& Furman; Furman, 2002; Meeus, Branje, van der Valk, \& de Wied, 2007).

The quality of adolescents' relationships with parents and friends is associated to the quality of romantic relationships in late adolescence and young adulthood (Connolly, 
Furman, \& Konarski, 2000; Connolly \& Johnson, 1996; Furman, Simon, Schaffer, \& Bouchey, 2002; Meeus et al., 2007; Roisman, Booth-LaForce, Cauffman, \& Spieker, 2009; Scharf \& Mayseless, 2001; Seiffge-Krenke, Shulman, \& Klessinger, 2001; Shulman \& Scharf, 2000). It is therefore important to longitudinally investigate the unique associations between the qualities of these relationships to distinguish precursors of committed romantic relationships. In this study, we longitudinally examine associations between romantic relationship commitment and commitment to parents and friends during adolescence. We will focus on commitment in relationships to parents, friends, and romantic partners. Commitment is defined as the intent to maintain a relationship, including a strong psychological attachment and a long-term orientation towards the relationship (Rusbult, Martz, \& Agnew, 1998). Adolescents are more committed when they are more satisfied with the relationship, when they have made investments in the relationship that may be lost if the relationship ends, and when they have poor alternatives to the relationship.

\section{Associations between Commitment to Parents, Friends, and Romantic Partners}

Parent-adolescent relationships and friendships differ in structural characteristics that may affect the mechanisms through which they are related to romantic relationships. Firstly, relationships with parents can be described as closed-field or involuntary. They are partly defined and constrained by kinship and entail lengthy interaction histories and routinized interactional scripts (Berscheid, 1985; Laursen, 1996). Adolescents' friendships are open-field or voluntary relationships that are formed and dissolved without biological or legal constraints. Secondly, friendships are more horizontal and equal than parent-adolescent relationships. Thus, commitment to parents is to some extent involuntary. In contrast, like commitment to romantic partners, commitment to friends is voluntary and part of a horizontal relationship characterized by equality.

Most theories on development of romantic relationships focus on the role of parent-adolescent relationship quality in romantic relationships. According to attachment theory (Bowlby, 1969), young children construct working models of attachment, or mental representations of the self, attachment figures, and relationships, based on the relationships with their parents (Ainsworth \& Bowlby, 1991; Furman et al., 2002), Adolescents will use these working models to understand and construct their relationships with romantic partners (Furman et al., 2002; Hazan \& Shaver, 1987). Thus, working models based on parent-adolescent relationships will tend to generalize to later romantic relationships (Schneider, Atkinson, \& Tardiff, 2001), and perceptions of commitment to parents should be positively associated to romantic relationship commitment.

In contrast to parent-adolescent relationships, friendships form a context in which adolescents can practice egalitarian and symmetrical relationship skills that they will need in their future adult life (Graziano, 1984; Laursen \& Bukowski, 1997). The specific characteristics of romantic relationships resemble those of friendships, as both relationships are voluntary and egalitarian in nature and encompass feelings of intimacy and companionship (Furman, 1999; Furman \& Wehner, 1994; Furman et al., 2002; Scharf \& Mayseless, 2001). It is therefore expected that egalitarian relationship skills that characterize friendships serve as a model for and are generalized to romantic relationships (Bouchey \& Furman, 2003; Oswald, Clark, \& Kelly, 2004; Schaffer, 2003). This suggests a positive association between commitment in adolescent friendships and commitment in romantic relationships. 


\section{Age Differences}

Over the course of adolescence, relationships with parents and friends change. Whereas relationships with parents become more egalitarian (De Goede, Branje, \& Meeus, 2009b), friendships become more supportive and intense (De Goede, Branje, \& Meeus, 2009a). In adolescent romantic relationships too, developmental phases can be distinguished from romantic relationships characterized by temporal fun to futureoriented romantic relationships (Bouchey \& Furman, 2003). Towards late adolescence, romantic relationships become more salient and gain more psychological value (Meeus et al., 2007; Nieder \& Seiffge-Krenke, 2001; Seiffge-Krenke, 2003). Parentadolescent relationships and adolescent romantic relationships become more similar towards late adolescence (Nieder \& Seiffge-Krenke, 2001), because romantic relationships attain real attachment qualities in late adolescence. Due to the developmental changes in these close relationships, it is to be expected that associations between romantic relationship quality and relationship quality with parents and friends also change over time.

Although earlier studies showed positive correlations between parent-adolescent relationship quality and adolescent romantic relationships, some studies failed to find these associations (Meeus et al., 2007; Seiffge-Krenke et al., 2001; Shulman \& Scharf, 2000), or only found these associations in late adolescence and early adulthood (Crockett \& Randall, 2006; Furman et al., 2002; Meeus et al., 2007; Seiffge-Krenke et al., 2001). For older adolescents and young adults, commitment in the parent-adolescent relationship may be more strongly related to relational commitment than for younger adolescents (Furman \& Wehner, 1994) because attachment processes become a more salient feature of romantic relationships in late adolescence and young adulthood. Also, relationships with parents become more egalitarian when adolescents become older (De Goede et al., 2009b) and therefore are more likely to serve as a model for romantic relationships in young adulthood than in adolescence (Seiffge-Krenke, 2003). Therefore, we expect the associations between relationships with parents and relationships with romantic partners to become stronger during adolescence.

At the same time, parent-adolescent relationships become more equitable over time (McGue, Elkins, Walden, \& Iacono, 2005; Russell, Pettit, \& Mize, 1998), and adolescents become increasingly autonomous (Blos, 1979; Grotevant \& Cooper, 1986). Because closeness and interdependence in friendships increase (Selman, 1981; Shulman, Laursen, Kalman, \& Karpovsky, 1997), adolescent friendships are likely to become more salient and influencing over time. As a consequence, it is possible that during adolescence, the relative influence of parent-adolescent relationships on romantic relationship commitment diminishes whereas the relative influence of friendships increases as adolescents grow older. Based on these notions, we expect that the link between commitment to parents and romantic relationship commitment is stronger in early-to-middle adolescence and that the link between commitment to friends and romantic relationship commitment is stronger in middleto-late adolescence.

\section{Aims of the Present Study}

In the current study, we will longitudinally examine linkages over time between commitment towards romantic partners at ages 16 and 20 and developmental changes in commitment to parents and friends from age 12 to 16 and from age 16 to 20 . 
Furthermore, we will explore age and gender differences with respect to these associations. Our main research questions are:

(1) How are commitment to parents and commitment to friends associated to romantic relationship commitment? We expect that commitment to parents will be positively related to romantic relationship commitment (hypothesis 1) and that commitment to friends will be positively related to romantic relationship commitment (hypothesis 2).

(2) Are there any age differences regarding the linkages over time between commitment to parents and friends and romantic relationship commitment? Based on earlier studies and theoretical notions (e.g., attachment theory), we expect the link between commitment to parents and romantic relationship commitment to be stronger in late adolescence (hypothesis 3). Based on another line of thinking, we expect the link between commitment to parents and romantic relationship commitment to be stronger in early-to-middle adolescence (hypothesis 4) whereas we expect the link between commitment to friends and romantic relationship commitment to be stronger in middle-to-late adolescence (hypothesis 5).

(3) Are there gender differences regarding the linkages over time between commitment to parents and friends and romantic relationship commitment? Because relationships of girls are more intensive than relationships of boys, it is possible that the associations between commitments in the different types of relationships are stronger for girls as well. Because no earlier studies have addressed this issue, we will investigate these gender differences exploratively.

\section{Method}

\section{Participants}

Participants were 403 adolescents that were involved in a romantic relationship at the fifth measurement wave of the longitudinal research project COnflict And Management Of RElationships (Meeus et al., 2004). The longitudinal sample consisted of a total of 1341 participants: 648 boys (48.3 percent) and 69 girls (51.7 percent). Two age groups were represented: 951 early adolescents (70.9 percent), who were on average 12.4 years of age $(S D=.58)$ and 390 middle adolescents $(29.1$ percent), who were on average 16.7 years of age $(S D=.80)$ during the first wave of measurement. Because both age groups were assessed during five measurement waves, a total age range from 12 to 16 and from 16 to 20 was available.

This sample consisted of a total of 142 boys (35.2 percent) and 261 girls (64.8 percent). In line with the original longitudinal sample, in the subsample also, two age groups were represented. The early-to-middle adolescent group of the subsample consisted of 218 participants (54.1 percent), who were on average 12.4 years of age $(S D=.57)$ during the first wave of assessment and 16.4 years of age $(S D=.57)$ during the fifth wave of assessment. The middle-to-late adolescent group of the subsample consisted of 185 participants (45.9 percent), who were on average 16.7 years of age $(S D=.84)$ during the first wave of assessment and 20.7 years of age $(S D=.89)$ during the fifth wave of assessment. The early-to-middle adolescent group consisted of 85 boys (39.0 percent) and 133 girls (61.0 percent). The middle-to-late adolescent group consisted of 57 boys (30.8 percent) and 128 girls (69.2 percent). Because both age groups were assessed during five measurement waves, also in the subsample, a total age range from 12 to 16 and from 16 to 20 was available. 
Most participants were Dutch (88.4 percent), and others identified themselves as part of a Dutch non-western ethnic minority group. At time 1, most participants lived with both parents (81.2 percent), others lived with their mother (13.1 percent), their father (2.4 percent), or without either of their parents (3.4 percent). The participants were in junior high and high schools at time 1 . In the year when the current study was initiated (2001), 21 percent of all Dutch early-to-middle adolescents, and 22 percent of the Dutch middle-to-late adolescents, belonged to ethnic minority groups (Statistics Netherlands, 2008a). Thus, ethnic minorities were slightly underrepresented in our sample. With regard to education, all participants initially were in junior high and high schools. Because of the sample recruitment procedure, 100 percent of our middle-tolate adolescents were in high school or college whereas national demographic statistics (Statistics Netherlands, 2008a, 2008b, 2008c) reveal that 96 percent of the Dutch middle-to-late adolescents were in some form of education during the time period covered by the current study (i.e., 2001-2005).

The early-and-middle adolescent groups were comparable regarding ethnic group $\left[\chi^{2}(4, \mathrm{~N}=380)=8.5, p=.07\right]$, living situation with parents $\left[\chi^{2}(5, \mathrm{~N}=382)=6.3, p=\right.$ $.28]$, and $\operatorname{sex}\left[\chi^{2}(1, N=398)=3.1, p=.08\right]$. Sample attrition was 3.6 percent from wave 1 to wave 5. The models in this study were estimated in Mplus 6 (Muthén \& Muthén 1998-2010) with a robust maximum-likelihood estimation method (Satorra \& Bentler, 1994) to provide better estimations of standard errors.

\section{Procedure}

The participating adolescents were recruited from various randomly selected schools for secondary education in the province of Utrecht, the Netherlands. Before the study, adolescents and their parents received written information describing the research project and goals and explaining the possibility to decline from participation. Both parents and adolescents provided informed consent. More than 99 percent of the approached high school students decided to participate. From 2001 onwards, data collection took place in five measurement waves with a 1-year interval between each of the waves. The participants completed the questionnaires at their own high school or at home, during annual assessments. Confidentiality of responses was guaranteed. Verbal and written instructions were offered. The adolescents received $€ 10$ as a reward for every wave they participated in.

For the questionnaire on commitment to friends, participants were asked to identify their best friend and answer the items while thinking about the relationship with this friend. It was explicitly asked not to select a romantic partner as their best friend. Participants were not restricted to select a same-age, same-school, or same-gender friend.

\section{Measures}

Commitment in Relationships with Parents and Friends. At all five measurement waves, commitment to parents and friends was measured with a short version of the commitment scale of a Dutch adaptation of the investment model scale (Rusbult et al., 1998) for relationships with mothers, fathers, and friends separately. This instrument is designed to measure commitment level, satisfaction level, investment size, and quality of alternatives and has a good reliability and validity (Rusbult et al., 1998). The commitment level scale addresses whether the adolescent is sufficiently attached to the relationship and whether the adolescent intents to maintain the relationship in the 
future to measure commitment to this relationship. The scale was assessed with four items. An example of a commitment item is: 'I invested much in the relationship with my mother'. Answers were indicated on a 5-point Likert scale (ranging from $1=$ not correct at all to $5=$ entirely correct). Internal consistencies were high with alphas ranging from .86 to .89 for relationships with mothers, alphas ranging from .87 to .91 for relationships with fathers, and alphas ranging from .86 to .87 for relationships with friends. Commitment to fathers and mothers was correlated significantly, with coefficients ranging from .38 to .56 across waves for early adolescents and from .33 to .52 for middle adolescents.

Commitment in Romantic Relationships. Commitment in romantic relationships was measured at the fifth measurement wave with the commitment scale of the Utrechtmanagement of identity commitments scale (Meeus, 2001). The scale measures to which extent adolescents feel committed to the relationship with their intimate partner. The commitment scale consists of five items. Answers were given based on a 5-point Likert scale (ranging from $1=$ entirely correct to $5=$ not correct at all) and were recoded to match the scale of commitment to parents and friends (ranging from $1=$ not correct at all to $5=$ entirely correct). An example item is: 'My partner gives me certainty in life'. Concurrent validity of the relational commitment scale has been demonstrated in two samples (Meeus \& 't Hart, 1993; Rispens, Hermanns, \& Meeus, 1996). Of this instrument, only data from the fifth measurement wave were used to maximize the number of participants in the study. Internal consistency was high with an alpha of .91 in wave 5 .

\section{Results}

\section{Preliminary Analyses}

We conducted a comparison of gender, age, and ethnicity between participants with and without a romantic relationship at wave 5 . We found a significant gender difference in both the early-to-middle adolescent group $\left[\chi^{2}(1, \mathrm{~N}=951)=14.65, p=.00\right]$ and the middle-to-late adolescent group $\left[\chi^{2}(1, \mathrm{~N}=390)=21.44, p=.00\right]$, with more girls than boys in a romantic relationship. We did not find significant differences regarding mean age and ethnicity in the early-to-middle adolescent group [age: $t(945)=-.09, p=.93$; ethnicity: $\chi^{2}(4, \mathrm{~N}=916)=1.22, p=.87$ ] or in the middle-to-late adolescent group [age: $t(388)=-.23, p=.82$; ethnicity: $\left.\chi^{2}(4, \mathrm{~N}=377)=9.07, p=.06\right]$.

In both age groups, we found no differences between adolescents with and without a romantic relationship in commitment to mothers and commitment to fathers at wave 5: for early-to-middle adolescent group, $t(905)=.03, p=.98$ and $t(871)=1.36, p=.17$, respectively, and for middle-to-late adolescent group, $t(358)=-1.36, p=.17$ and $t(350)$ $=.21, p=.84$, respectively. Adolescents with a romantic partner were, however, more committed to their best friend compared with adolescents without a romantic partner in both age groups: for early-to-middle adolescent group, $t(904)=-2.67, p=.01$ ), and for middle-to-late adolescent group, $t(354)=-2.76, p=.01$.

\section{Descriptive Statistics}

Table 1 provides the means and standard deviations for the observed values of the variables commitment to parents and commitment to friends on the five measurement 
Romantic Relationship Commitment 431

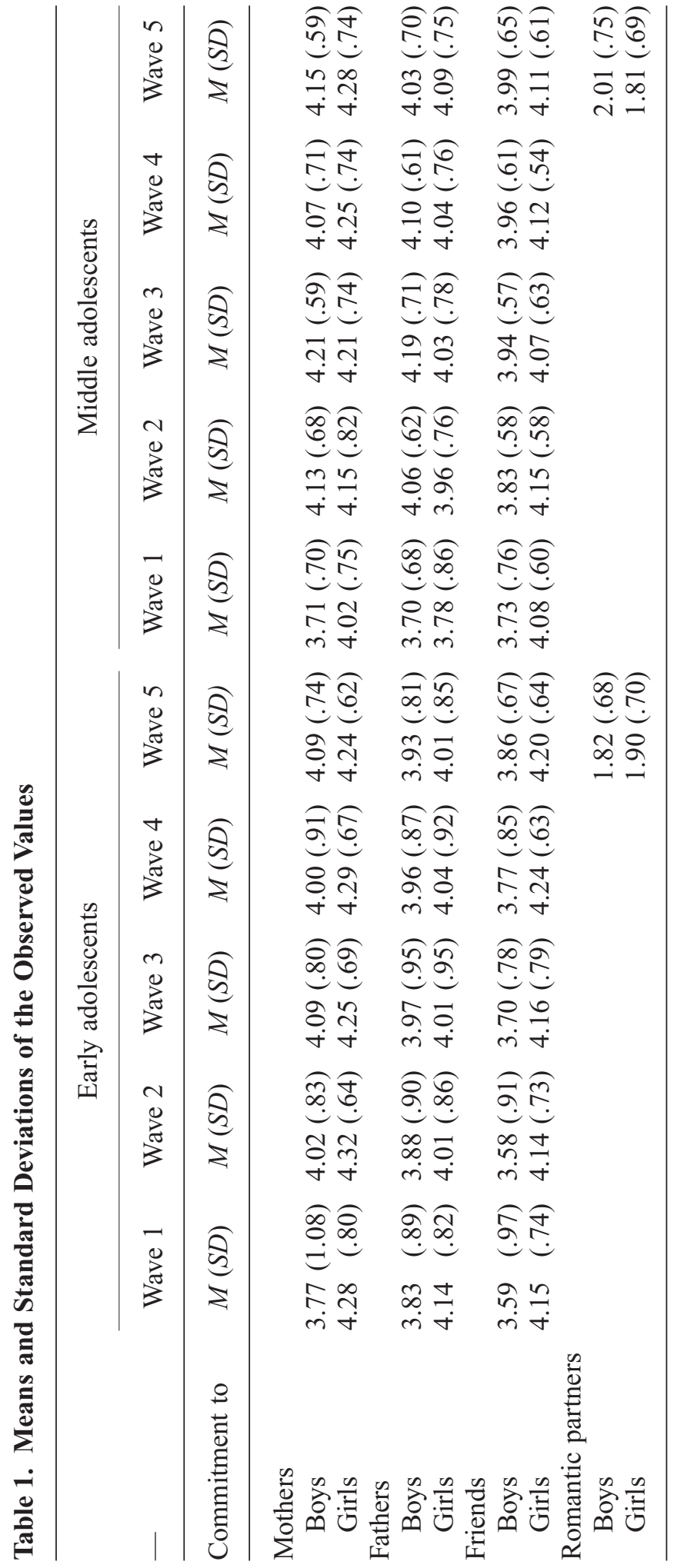


waves for the early and the middle adolescents and for boys and girls separately. In addition, this table shows the means and standard deviations for the observed values of commitment to romantic partners at the fifth measurement wave, also for the early and the middle adolescents and for boys and girls separately.

We analyzed differences in commitment to fathers, mothers, and friends using a repeated measures analysis of variance with time and relationship as within subject factor and sex and age cohort as between subject factor. The significant main effect of relationship, $F(2,594)=9.79, \eta_{\mathrm{p}}{ }^{2}=.031$, showed that commitment to mothers across the waves is significantly higher than commitment to fathers and friends. Commitment to fathers and friends did not differ. The interaction between relationship and sex was also significant, $F(2,594)=6.94, \eta_{\mathrm{p}}{ }^{2}=.023$. For boys, commitment to mothers did not differ from father, and commitments to mother and father were higher than commitment to friends. For girls, commitment to mothers was significantly higher than commitment to fathers and friends, and commitment to friends was significantly higher than commitment to fathers. No other interactions with relationship reached significance.

Table 2 shows the correlations between all variables included in the longitudinal models.

\section{Multivariate Latent Growth Models}

To examine romantic relationship commitment and its linkages with commitment to parents and friends, we used a multivariate latent growth model (Duncan, Duncan, Strycker, Li, \& Alpert, 1999; McArdle \& Epstein, 1987). In this model, one latent growth curve was estimated for adolescents' commitment to parents based on the combined observed scale scores of adolescents' commitment to both mothers and fathers on wave 1-5. In the same model, another latent growth curve was estimated for adolescents' commitment to friends based on the observed scale scores on this variable on wave $1-5$. In the latent growth curve for both commitment to parents and commitment to friends, the annual measurements are indicators of two latent growth factors: the intercept, representing the base level, and the slope, representing the rate of change. In the multivariate model, the two intercepts of commitment to parents and commitment to friends and the two slopes of commitment to parents and commitment to friends were linked with each other (see Figure 1). We also added covariance paths of these growth factors with romantic commitment at wave 5 to test whether romantic relationship commitment is associated with base levels of commitment to parents and friends and with rates of change of commitment to parents and friends. A four-group design was used to distinguish among early-to-middle adolescent boys, early-tomiddle adolescent girls, middle-to-late adolescent boys, and middle-to-late adolescent girls. Within-time correlations between error terms of commitment to parents and those of observed variables of commitment to friends were added to the model. Although we tested both linear and curvilinear growth curve models, we decided to use the linear models due to estimation problems with the curvilinear models. These linear models fitted the data adequately (see Table 3).

We used model comparisons to investigate age and gender differences and to maintain the model as parsimonious as possible. In the baseline model, the four groups were constrained to be completely similar, except for the within-time error correlations. Subsequently, we released the estimates of the means, variances, and covariances across the four groups in a stepwise manner. Finally, we tested whether covariances between commitment to parents and romantic relationship commitment could be 


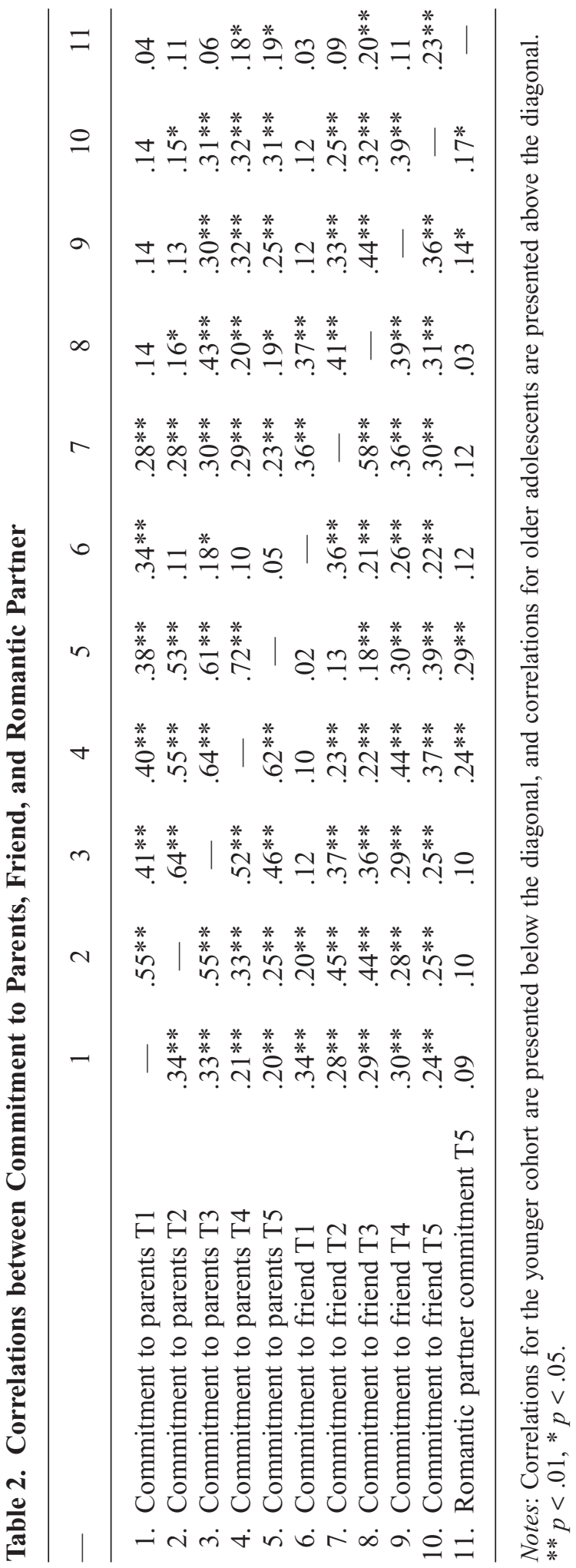


434 Irene H. A. De Goede, Susan Branje, Jet van Duin et al.

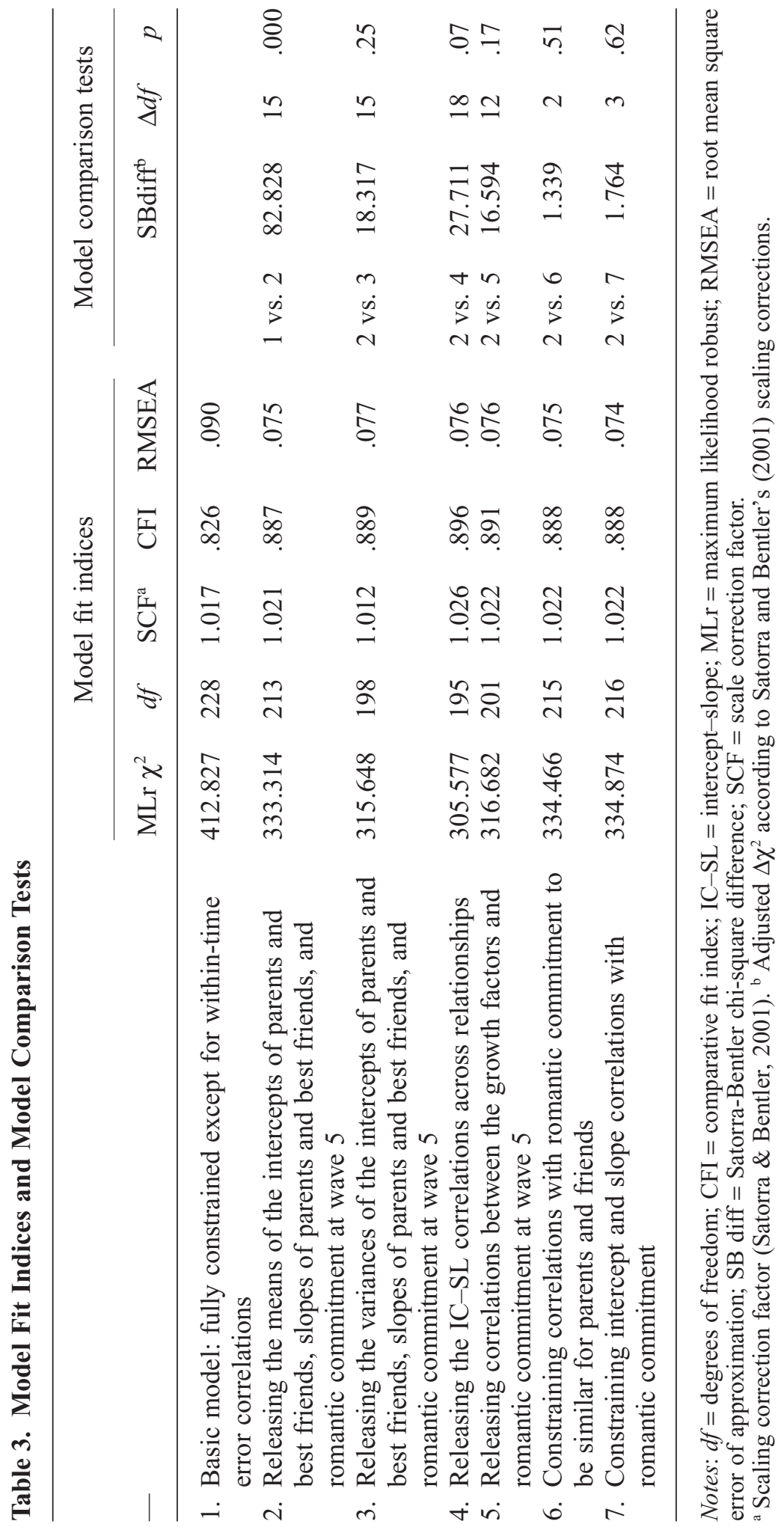


Table 4. Results of Multigroup Multivariate Latent Growth Curve Model

\begin{tabular}{|c|c|c|c|c|}
\hline \multirow[b]{2}{*}{ - } & \multicolumn{2}{|c|}{ Early to middle } & \multicolumn{2}{|c|}{ Middle to late } \\
\hline & Boys & Girls & Boys & Girls \\
\hline \multicolumn{5}{|l|}{ Parents } \\
\hline IC $M$ & $3.906 * *$ & $4.178 * *$ & $3.948 * *$ & $3.957 * *$ \\
\hline $\mathrm{IC} \sigma^{2}$ & $.260 * *$ & $.260 * *$ & $.260 * *$ & $.260 * *$ \\
\hline SL $M$ & .032 & -.012 & .047 & $.065 * *$ \\
\hline $\mathrm{SL} \sigma^{2}$ & $.017 * *$ & $.017 * *$ & $.017 * *$ & $.017 * *$ \\
\hline \multicolumn{5}{|l|}{ Friends } \\
\hline IC $M$ & $3.531 * *$ & $4.155 * *$ & $3.804 * *$ & $4.100 * *$ \\
\hline $\mathrm{IC} \sigma^{2}$ & $.225 * *$ & $.225 * *$ & $.225 * *$ & $.225^{* *}$ \\
\hline SL $M$ & $.082 * *$ & .013 & .052 & .000 \\
\hline SL $\sigma^{2}$ & $.015 * *$ & $.015 * *$ & $.015 * *$ & $.015 * *$ \\
\hline \multicolumn{5}{|l|}{ Romantic Partners } \\
\hline W5 $M$ & $4.197 * *$ & $4.097 * *$ & $3.986 * *$ & $4.183 * *$ \\
\hline W5 $\sigma^{2}$ & $.485 * *$ & $.485 * *$ & $.485 * *$ & $.485^{* *}$ \\
\hline IC-IC correlation & $.499 * *$ & $.499 * *$ & $.499 * *$ & $.499 * *$ \\
\hline \multicolumn{5}{|l|}{ IC-SL correlations } \\
\hline IC parents $\leftrightarrow$ SL parents & $-.413 * *$ & $-.413 * *$ & $-.413 * *$ & $-.413 * *$ \\
\hline IC friends $\leftrightarrow$ SL friends & $-.620 * *$ & $-.620 * *$ & $-.620 * *$ & $-.620 * *$ \\
\hline IC parents $\leftrightarrow$ SL friends & $-.123 *$ & $-.123 *$ & $-.123 *$ & $-.123^{*}$ \\
\hline IC friends $\leftrightarrow$ SL parents & $-.301 * *$ & $-.301 * *$ & $-.301 * *$ & $-.301 * *$ \\
\hline SL-SL correlation & $.501 * *$ & $.501 * *$ & $.501 * *$ & $.501 * *$ \\
\hline \multicolumn{5}{|l|}{ IC/SL-Romantic partners } \\
\hline IC parents $\leftrightarrow$ partners W5 & $.054 * *$ & $.054 * *$ & $.054 * *$ & $.054 * *$ \\
\hline IC friends $\leftrightarrow$ partners W5 & $.057 * *$ & $.057 * *$ & $.057 * *$ & $.057 * *$ \\
\hline SL parents $\leftrightarrow$ partners W5 & $.207 * *$ & $.207 * *$ & $.207 * *$ & $.207 * *$ \\
\hline SL friends $\leftrightarrow$ partners W5 & $.223 * *$ & $.223 * *$ & $.223 * *$ & $.223 * *$ \\
\hline
\end{tabular}

Notes: All variances and correlations were constrained to be similar across the four groups. Correlations between growth parameters and romantic relationship commitment at wave 5 were also constrained to be similar for relationships with parents and friends. IC = intercept; SL = slope; W5 = wave 5 .

$* p<.05, * * p<.01$.

constrained to be similar to the covariances between commitment to friends and romantic relationship commitment. Using chi-square difference tests, we determined which parameter releases made a significant improvement to the model fit. The parameter releases that turned out to be a non-significant improvement to the model fit were again constrained to be similar in subsequent steps. Based on this strategy, all means were released to be different for the four groups, but all correlations could be constrained to be similar for all four groups. That is, the intercept-slope correlations across commitment to parents and commitment to friends as well as paths with romantic relationship commitment were constrained to be similar across the four groups. Table 3 shows the model comparison tests and the model fit indices of the different models. Results and fit indices of the best-fitting model are displayed in Table 4 and Figure 1. 


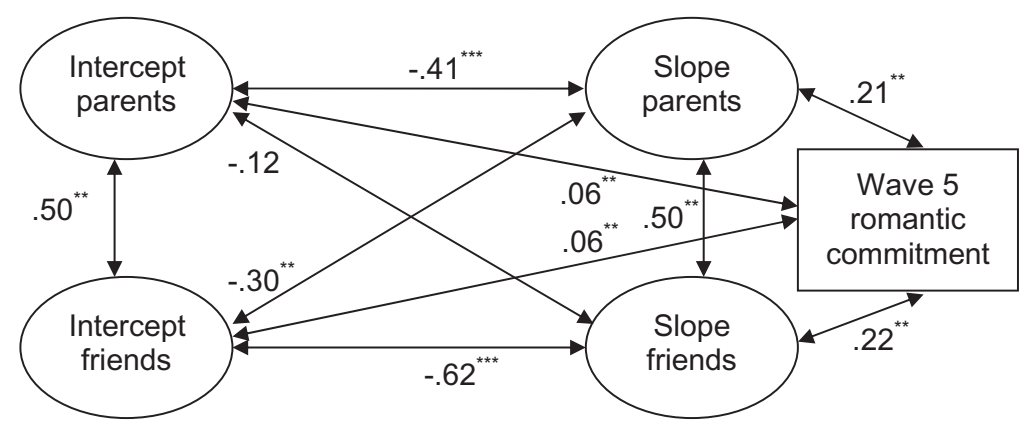

Figure 1. Correlations between Intercepts and Slopes of Commitment to Parents and Friends and Romantic Relationship Commitment at Wave 5.

Notes: $* p<.05, * * p<.01$.

\section{Commitment to Parents and Commitment to Friends over Time}

Commitment to parents increased significantly from middle to late adolescence for girls. Commitment to friends increased from early to middle adolescence for boys. No other significant changes in commitment to parents and friends were found. However, the variance in growth of commitment was significant for all groups for both commitment to friends and commitment to parents. Therefore, we could examine how interindividual differences in change in commitment were related to romantic partner commitment.

In both age cohorts, the intercepts of commitment to parents and commitment to friends correlated positively, indicating that the base levels of adolescents' commitment to both parents and friends are related. In addition, the slopes of commitment to parents and friends correlated positively, indicating that the developmental changes of commitment to parents and friends are related.

In both age cohorts, the intercept (base level) and slope (rate of change) of commitment to parents correlated negatively and also the intercept and slope of commitment to friends correlated negatively. This indicates that in both parent-adolescent relationships and adolescent friendships, a higher base level of commitment is related to a smaller increase or larger decrease of commitment over time, suggesting regression to the mean: adolescents who already are highly committed to a relationship do not become that much more committed over time. Furthermore, a higher base level of commitment to friends was related to a smaller increase or a larger decrease in commitment to parents. This means that adolescents who are initially highly committed to their friends become relatively less committed to their parents compared with adolescents who initially show less commitment towards their friends. All other intercept-slope correlations were non-significant.

\section{Linkages between Commitment to Parents and Friends and Romantic Relationship Commitment}

The intercept and slope of commitment to parents and friends are significantly and positively related to romantic relationship commitment at wave 5 . This means that higher base levels and larger developmental changes in commitment to parents and 
friends are related to higher romantic relationship commitment at wave 5, thereby confirming hypotheses 1 and 2 . All these paths could be constrained to be similar for all groups, indicating that there were no age or gender differences with respect to these findings. Thus, the results reject our hypotheses that the link between commitment to parents and romantic relationship commitment would be stronger in late adolescence (hypothesis 3), that romantic relationship commitment would be stronger linked to commitment to parents than to commitment to friends in early-to-middle adolescence (hypothesis 4), and that romantic relationship commitment would be stronger linked to commitment to friends than to commitment to parents in middle-to-late adolescence (hypothesis 5). Furthermore, we could constrain the paths between the intercepts and slopes of commitment with parents and friends and romantic relationship commitment to be similar, which indicates that commitment to parents and commitment to friends are related to romantic relationship commitment with similar strength.

\section{Discussion}

This study aimed to investigate romantic relationship commitment in middle and late adolescence and its linkages with commitment to parents and friends over time. The results confirm that romantic relationships in adolescence reflect earlier and current relationship experiences with parents and friends (Furman et al., 2002), as both base levels and developmental changes of commitment to parents and friends are positively related to romantic relationship commitment. However, the linkages with romantic relationship commitment were equally strong across age cohorts and gender, suggesting that romantic relationships may be as salient in middle adolescence as in late adolescence.

The results of this study confirm our expectations that base levels and developmental changes of commitment to parents and friends are positively associated to commitment to romantic partners at the end of the 4-year period of this study. These findings are in line with earlier studies (e.g., Conger, Cui, Bryant, \& Elder, 2000; Furman et al., 2002; Scharf \& Mayseless, 2001; Seiffge-Krenke, 2006). Moreover, they extend the current knowledge by showing that commitment to parents and friends in early adolescence is associated to romantic relationship commitment in middle adolescence (see also Roisman et al., 2009), and that commitment to parents and friends in middle adolescence is associated to romantic relationship commitment in late adolescence. So, not only changes in commitment to parents and friends up to concurrent levels of commitment are important for romantic relationship commitment, earlier levels of commitment are important as well.

The lack of differences in associations for early-to-middle and middle-to-late adolescents contradicted our expectation that associations of commitment to parents with romantic partner commitment are stronger towards late adolescence. Combined with the lack of differences in commitment to parents for adolescents with and without a romantic partner, these findings suggest that romantic involvement is a normative part of development in both middle and late adolescence (cf. Roisman et al., 2009). Involvement in romantic relationships is quite common among middle adolescents and even more common among late adolescents (Collins, Welsh, \& Furman, 2009). Although excessive involvement in romantic relationships may be negatively related to quality of relationships to parents (Roisman et al., 2009), mere involvement in romantic relationships during this age period may just reflect the saliency of these relationships but does not necessarily reflect the quality of the parent-adolescent 
relationship. To the extent that adolescents are involved in romantic relationships, more committed relationships with parents generalize to more committed relationships with romantic partners.

Also, we did not find differences in the relative strength of the positive associations between commitment to parents and friends and romantic relationship commitment across age groups. These results are not in line with our prediction that commitment to parents is more important for commitment to romantic partners in early-to-middle adolescence whereas commitment to friends is more important for commitment to romantic partners in middle-to-late adolescence. Instead, it seems that commitment to parents and commitment to friends are related to romantic relationship commitment equally strong and that this pattern of associations is stable throughout adolescence. Although several studies found positive correlations of romantic relationships with parent-adolescent relationships (Connolly \& Johnson, 1996; Crockett \& Randall, 2006; Furman et al., 2002; Meeus et al., 2007; Roisman et al., 2009; Seiffge-Krenke et al., 2001), and friendships (Connolly et al., 2000; Furman et al., 2002; Roisman et al., 2009; Scharf \& Mayseless, 2001; Seiffge-Krenke et al., 2001; Shulman \& Scharf, 2000), these studies did not systematically compare the relative contribution of relationships with parents and friends to romantic relationships. This finding, combined with the positive associations between commitment to parents and commitment to friends, supports the notion of a stable and general attachment perspective in which adolescents use the same working model of relationships for different types of relationships (Furman et al., 2002; Hazan \& Shaver, 1987; Schneider et al., 2001). Parent and peer influences tend to act in concert with each other with respect to romantic relationships. Our findings suggest that the working model of adolescents' relationships to parents is important for romantic relationships across adolescence, but at the same time, the modeling role of horizontal, voluntary relationships with friends contributes significantly to romantic relationship experiences throughout adolescence. Although the differential contribution of parents and friends to romantic relationships is not evident in perceived commitment, perhaps in other aspects of romantic relationships, such as attachment functions or interaction behaviors, parents and friends do contribute differentially in different age periods.

\section{Gender Differences}

Possible gender differences regarding associations between commitment to parents and friends and romantic relationship commitment were investigated in an explorative manner in this study. Although more girls than boys were involved in a romantic relationship, the positive associations between commitment to parents and friends and romantic relationship commitment were similar for boys and girls. This shows that girls are ahead of boys regarding the timing of formation of romantic relationships, yet the processes leading to successful romantic relationships are identical for boys and girls.

\section{Strengths and Limitations}

A strong point of the current study is the inclusion of longitudinal data, which allowed us to include relations between developmental changes of commitment to parents and friends from age 12 to age 16 and from age 16 to age 20 and romantic relationship 
commitment at age 16 and 20. Also, the combined investigation of relationships with parents, friends, and romantic partners provides a relevant representation of the actual social contexts adolescents live in, thereby providing more information than assessments based on a single social context.

Despite the longitudinal design, this study was nevertheless limited by the inclusion of two groups of participants that were assessed over five measurement waves, instead of one group that was assessed from early to late adolescence. Also, we used two different measures to assess commitment: one for commitment to fathers, mothers, and friends, and one for romantic relationship commitment. Moreover, the data were based on self-reports of adolescents and therefore only describe the adolescents' perceptions of their relationships. This can be problematic considering that different informants often report different perceptions (Renk, Donelly, Klein, Oliveros, \& Baksh, 2008; Vierhaus \& Lohaus, 2008). Also, correlations between commitments in different relationships might be overstated due to shared reporter and method variance, as commitment to parents and commitment to friends were assessed with a similar instrument, and all three commitment measures were assessed by the same respondent. On the other hand, it has frequently been found that adolescents more accurately report about their relationships than, for example, parents (Collins \& Laursen, 2004). Also, relationship quality is for a large part in the 'eye of the beholder' (Branje, van Aken, \& van Lieshout, 2002), and adolescents' perceptions of their relationships might influence interactions and adolescent developmental outcomes. Nevertheless, using observations or multi-informant questionnaires could give more information on commitment in these relationships.

\section{Conclusions}

All in all, the current study reveals that higher base levels of commitment to parents and friends as well as increases in commitment to parents and friends were related to higher levels of romantic relationship commitment at the end of the 4-year period of this study. These positive associations were similar in early-to-middle adolescence and middle-to-late adolescence, suggesting that romantic relationships in both middle and late adolescence are salient and meaningful. Adolescents are better able to maintain committed romantic relationships when they have higher quality relationships to parents and friends. Finally, it seems that both parent-adolescent relationships and friendships are equally important regarding the formation of committed romantic relationships in adolescence. This means that both relational contexts are necessary for the development of romantic relationships, from the emergence of romantic interest to a serious and long-lasting romantic relationship.

\section{References}

Ainsworth, M. D. S., \& Bowlby, J. (1991). An ethological approach to personality development. American Psychologist, 46, 331-341.

Berscheid, E. (1985). Interpersonal attraction. In G. Lindzey \& E. Aronson (Eds.), Handbook of social psychology (3rd ed., pp. 413-484). New York: Random House.

Blos, P. (1979). The adolescent passage: Developmental issues. New York: International Universities Press.

Bouchey, H. A., \& Furman, W. (2003). Dating and romantic experiences in adolescence. In G. R. Adams \& M. D. Berzonsky (Eds.), Blackwell handbook of adolescence (pp. 313-329). Oxford: Blackwell Publishing. 
Bowlby, J. (1969). Attachment and loss: Vol. 1. Attachment. New York: Basic Books.

Branje, S. J. T., van Aken, M. A. G., \& van Lieshout, C. F. M. (2002). Relational support in families with adolescents. Journal of Family Psychology, 16, 351-362.

Collins, W. A., \& Laursen, B. (2004). Changing relationships, changing youth: Interpersonal contexts of adolescent development. Journal of Early Adolescence, 24, 55-62.

Collins, W. A., Welsh, D. P., \& Furman, W. (2009). Adolescent romantic relationships. Annual Review of Psychology, 60, 631-652.

Conger, R. D., Cui, M., Bryant, C. M., \& Elder, G. H. (2000). Competence in early adult romantic relationships: A developmental perspective on family influences. Journal of Personality and Social Psychology, 79, 224-237.

Connolly, J., Furman, W., \& Konarski, R. (2000). The role of peers in the emergence of heterosexual romantic relationships in adolescence. Child Development, 71, 13951408.

Connolly, J., \& Johnson, A. (1996). Adolescents' romantic relationships and the structure and quality of their close personal ties. Personal Relationships, 3, 185-195.

Crockett, L. J., \& Randall, B. A. (2006). Linking adolescent family and peer relationships to the quality of young adult romantic relationships: The mediating role of conflict tactics. Journal of Social and Personal Relationships, 23, 761-780.

De Goede, I. H. A., Branje, S. J. T., \& Meeus, W. H. J. (2009a). Developmental changes and gender differences in adolescents' perceptions of friendships. Journal of Adolescence, 32, $1105-1123$.

De Goede, I. H. A., Branje, S. J. T., \& Meeus, W. H. J. (2009b). Developmental changes in adolescents' perceptions of relationships with their parents. Journal of Youth and Adolescence, $38,75-88$.

Duncan, T. E., Duncan, S. C., Strycker, L. A., Li, F., \& Alpert, A. (1999). An introduction to latent variable growth curve modeling: Concepts, issues, and applications. Mahwah, NJ: Lawrence Erlbaum Associates.

Erikson, E. (1968). Identity, youth, and crisis. New York: Norton.

Furman, W. (1999). The role of peer relationships in adolescent romantic relationships. In W. A. Collins \& B. Laursen (Eds.), Minnesota symposium on child development: Vol. 29. Relationships as developmental contexts (pp. 172-202). Hillsdale, NJ: Erlbaum.

Furman, W. (2002). The emerging field of adolescent romantic relationships. Current Directions in Psychological Science, 11, 177-180.

Furman, W., Simon, V. A., Schaffer, L., \& Bouchey, H. A. (2002). Adolescents' working models and styles for relationships with parents, friends, and romantic partners. Child Development, $73,241-255$.

Furman, W., \& Wehner, E. (1994). Romantic views: Toward a theory of adolescent romantic relationships. In R. Montemayor, G. Adams, \& G. Gullota (Eds.), Relationships during adolescence (pp. 168-195). Thousand Oaks, CA: Sage.

Graziano, W. G. (1984). A developmental approach to social exchange processes. In J. C. Masters, \& K. Yarkin-Levin (Eds.), Boundary areas in social and developmental psychology. Orlando, FL: Academic Press.

Grotevant, H. D., \& Cooper, C. R. (1986). Individuation in family relationships: A perspective on individual differences in the development of identity and role-taking skill in adolescence. Human Development, 29, 82-100.

Hazan, C., \& Shaver, P. R. (1987). Romantic love conceptualized as an attachment process. Journal of Personality and Social Psychology, 52, 511-524.

Laursen, B. (1996). Closeness and conflict in adolescent peer relationships: Interdependence with friends and romantic partners. In W. M. Bukowski, A. F. Newcomb, \& W. W. Hartup (Eds.), The company they keep: Friendship in childhood and adolescence (pp. 186-210). Cambridge: Cambridge University Press.

Laursen, B., \& Bukowski, W. M. (1997). A developmental guide to the organisation of close relationships. International Journal of Behavioral Development, 21, 747-770.

McArdle, J. J., \& Epstein, D. (1987). Latent growth curves within developmental structural equation models. Child Development, 58, 110-133.

McGue, M., Elkins, I., Walden, B., \& Iacono, W. G. (2005). Perceptions of the parentadolescent relationship: A longitudinal investigation. Developmental Psychology, 41, 971-984. 
Meeus, W. (2001). A three-dimensional measure of identity: The Utrecht-management of identity commitments scale (U-MICS). Unpublished Manuscript, Research Centre Adolescent Development, Utrecht University.

Meeus, W. H. J., Akse, J., Branje, S. J. T., Ter Bogt, T., Delsing, M., Van Doorn, M. D., et al. (2004). Codebook of the research project CONflict And Management Of RElationships (CONAMORE). Unpublished Manuscript, Utrecht University.

Meeus, W., Branje, S. J. T., van der Valk, I., \& de Wied, M. (2007). Relationships with intimate partner, best friend, and parents in adolescence and early adulthood: A study of the saliency of the intimate partnership. International Journal of Behavioral Development, 31, 449-460.

Meeus, W., \& 't Hart, H. (1993). Jongeren in Nederland [Young people in the Netherlands]. Amersfoort: Academische Uitgeverij.

Muthén, L. K., \& Muthén, B. O. (1998-2010). Mplus user's guide, 6th edn. Los Angeles, CA: Muthén and Muthén.

Nieder, T., \& Seiffge-Krenke, I. (2001). Coping with stress in different phases of romantic development. Journal of Adolescence, 24, 297-311.

Oswald, D. L., Clark, E. M., \& Kelly, C. L. (2004). Friendship maintenance behaviors: An analysis of individual and dyad behaviors. Journal of Social and Clinical Psychology, 23, 413-441.

Renk, K., Donelly, R., Klein, J., Oliveros, A., \& Baksh, E. (2008). Cross-informant ratings of the emotional and behavioral functioning of college students. Journal of Youth and Adolescence, 37, 193-210.

Rispens, J., Hermanns, J., \& Meeus, W. (Eds.) (1996). Opvoeden in Nederland [Parenting in the Netherlands]. Assen: Van Gorcum.

Roisman, G. I., Booth-LaForce, C., Cauffman, E., \& Spieker, S. (2009). The developmental significance of adolescent romantic relationships: Parent and peer predictors of engagement and quality at age 15. Journal of Youth and Adolescence, 38, 1294-1303.

Rusbult, C. E., Martz, J. M., \& Agnew, C. R. (1998). The investment model scale: Measuring commitment level, satisfaction level, quality of alternatives, and investment size. Personal Relationships, 5, 357-391.

Russell, A., Pettit, G. S., \& Mize, J. (1998). Horizontal qualities in parent-child relationships: Parallels with and possible consequences for children's peer relationships. Developmental Review, 18, 313-352.

Satorra, A., \& Bentler, P. M. (1994). Corrections to test statistics and standard errors in covariance structure analysis. In A. von Eye, \& C. C. Clogg (Eds.), Latent variables analysis: Applications for developmental research (pp. 399-419). Thousand Oaks, CA: Sage.

Satorra, A., \& Bentler, P. M. (2001). A scaled difference chi-square test statistic for moment structure analysis. Psychometrika, 66, 507-514.

Schaffer, H. R. (2003). Social development. Oxford: Blackwell Publishing.

Scharf, M., \& Mayseless, O. (2001). The capacity for romantic intimacy: Exploring the contribution of best friend and marital and parental relationships. Journal of Adolescence, 24, 379-399.

Schneider, B., Atkinson, L., \& Tardiff, C. (2001). Child-parent attachment and children's peer relations: A quantitative review. Developmental Psychology, 37, 86-100.

Seiffge-Krenke, I. (2003). Testing theories of romantic development from adolescence to young adulthood: Evidence of a developmental sequence. International Journal of Behavioral Development, 27, 519-531.

Seiffge-Krenke, I. (2006). Coping with relationship stressors: The impact of different working models of attachment and links to adaptation. Journal of Youth and Adolescence, 35, 2539.

Seiffge-Krenke, I., Shulman, S., \& Klessinger, N. (2001). Adolescent precursors of romantic relationships in young adulthood. Journal of Social and Personal Relationships, 18, 327346.

Selman, R. L. (1981). The child as friendship philosopher. In S. R. Asher \& J. M. Gottman (Eds.), The development of children's friendships (pp. 242-272). Cambridge, MA: Cambridge University Press.

Shulman, S., Laursen, B., Kalman, Z., \& Karpovsky, S. (1997). Adolescent intimacy revisited. Journal of Youth and Adolescence, 26, 597-617. 
442 Irene H. A. De Goede, Susan Branje, Jet van Duin et al.

Shulman, S., \& Scharf, M. (2000). Adolescent romantic behaviors and perceptions: Age- and gender-related differences, and links with family and peer relationships. Journal of Research on Adolescence, 10, 99-118.

Statistics Netherlands. (2008a). Statline: Bevolking naar Herkomst en Generatie. Voorburg, Netherlands: Statististics Netherlands.

Statistics Netherlands. (2008b). Statline: Mbo; leerlingen en geslaagden. Voorburg, The Netherlands: Statististics Netherlands.

Statistics Netherlands. (2008c). Statline: Vo; leerlingen en geslaagden. Voorburg, Netherlands: Statistics Netherlands.

Vierhaus, M., \& Lohaus, A. (2008). Children and parents as informants of emotional and behavioural problems predicting female and male adolescent risk behaviour: A longitudinal cross-informant study. Journal of Youth and Adolescence, 37, 211-224. 